\title{
Processos de formação e produção de conhecimento: cinco olhares sobre a Educação Popular e Saúde*
}

\author{
Helena Maria Scherlowski Leal David(a) \\ Ivanilde Vieira Batista ${ }^{(b)}$ \\ Julio Alberto Wong Um ${ }^{(c)}$ \\ Paulette Cavalcanti ${ }^{(d)}$ \\ Regina Helena Simões Barbosa ${ }^{(\mathrm{e})}$ \\ Selvino Heck ${ }^{(f)}$
}

David HMSL, Batista IV, Um JAW, Cavalcanti P, Barbosa RHS, Heck S. Education processes and knowledge production: five perspectives on Popular Education and Health. Interface (Botucatu). 2014;18 Supl 2:1579-1590.

For this issue of Interface, we interviewed five professionals whose origins and life histories are different, but whose praxis has been constructed around the principles of Popular Education and Health. These individuals are: Selvino Heck, Special Assessor of the General Secretary of the Presidency of Brazil, Director of the Popular Education and Activism Department of the National Secretariat of Social Articulation, and Executive Secretary of the National Agro-ecology and Organic Production Committee; Regina Helena Simões Barbosa, professor and researcher at the Public Health Institute of the Federal University of Rio de Janeiro; Ivanilde Batista, Staff member of the Health Department of the State of Goiás, founder and militant of ANEPS-GO; Paulette Cavalcanti, professor and researcher at the Oswaldo Cruz Foundation in Pernambuco; and Julio Alberto Wong Un, professor and researcher at the Public Health Institute of the Fluminense Federal University.

Keywords: Popular Education and Health. Social activism. Popular participation.
Neste suplemento da Interface, trazemos cinco entrevistados com histórias de origem e trajetos diferentes, mas cuja práxis se construiu e se constrói em torno dos princípios da Educação Popular e Saúde. São eles: Selvino Heck, atual assessor especial da Secretaria Geral da Presidência da República, diretor do Departamento de Educação Popular e Mobilização da Secretaria Nacional de Articulação Social da Secretaria Geral e secretário executivo da Comissão Nacional de Agroecologia e Produção Orgânica; Regina Helena Simões Barbosa, professora e pesquisadora do Instituto de Estudos de Saúde Coletiva da Universidade do Estado do Rio de Janeiro; Ivanilde Batista, servidora da Secretaria de Estado de Saúde de Goiás, fundadora e militante da Aneps-GO; Paulette Cavalcanti, professora e pesquisadora da Fundação Oswaldo Cruz em Pernambuco; e Julio Alberto Wong Un, professor e pesquisador do Instituto de Saúde Coletiva da Universidade Federal Fluminense.

Palavras-chave: Educação Popular e Saúde. Mobilização social. Participação popular.
* A entrevista fol organizada e conduzida por Helena Maria Scherlowski Leal David 


\section{Apresentação}

Falar sobre os processos de formação de profissionais de saúde, pessoas inseridas em movimentos populares, gestores de políticas públicas e outros atores impõe, desde o início, buscar contemplar a diversidade de experiências, projetos e práticas. Para a seção de Entrevistas deste número temático da Interface, em lugar de um, teremos cinco entrevistados, com histórias de origem e trajetos diferentes, mas cuja práxis se construiu e se constrói em torno dos princípios da Educação Popular e Saúde. São eles: Selvino Heck, atual assessor especial da Secretaria Geral da Presidência da República, diretor do Departamento de Educação Popular e Mobilização da Secretaria Nacional de Articulação Social da Secretaria Geral e secretário executivo da Comissão Nacional de Agroecologia e Produção Orgânica; Regina Helena Simões Barbosa, professora e pesquisadora do Instituto de Estudos de Saúde Coletiva da Universidade do Estado do Rio de Janeiro; Ivanilde Batista, servidora da Secretaria de Estado de Saúde de Goiás, fundadora e militante da Aneps-GO; Paulette Cavalcanti, professora e pesquisadora da Fundação Oswaldo Cruz em Pernambuco; e Julio Alberto Wong Un, professor e pesquisador do Instituto de Saúde Coletiva da Universidade Federal Fluminense.

Não faremos as suas apresentações: deixaremos que cada um entre na roda, apresente-se e fale de sua caminhada, destacando as principais questões em torno dos desafios à construção partilhada de saberes e da formação crítica para a conquista da saúde.

Selvino Heck - Sou filho de colono, agricultor familiar, de Santa Emília, Venâncio Aires, interior do Rio Grande do Sul, que ainda hoje come verduras e frutas tiradas do pé (mamãe e os irmãos mais novos continuam na roça e trabalham com Feira do Produtor) e curava muitas de suas doenças com ervas caseiras passadas por gerações. Fui (ou ainda sou) franciscano amante da paz e da natureza.

Em 1983, ajudei a fundar o Camp (Centro de Assessoria Multiprofissional), de Porto Alegre, ONG que ajudou a construir os principais movimentos sociais do Sul do Brasil. Morei por muitos anos nas vilas populares da Lomba do Pinheiro, trabalhando com pastorais populares e movimentos comunitários, sempre à base da Educação Popular freireana.

Como deputado estadual constituinte gaúcho, fui presidente da Comissão de Saúde da Assembleia Legislativa, tendo como assessora Maria Luíza Jaeger. Desde 2003, estou no governo federal, oito anos na Assessoria do Gabinete do presidente Lula, desde 2011, na Secretaria Geral da Presidência da República, coordenando a Rede de Educação Cidadã (Recid).

Sou conselheiro do Conselho Nacional de Segurança Alimentar (Consae) e membro da Câmara Interministerial respectiva. Desde o final de 2012, sou secretário executivo da Comissão Nacional de Agroecologia e Produção Orgânica e faço parte da Câmara Interministerial respectiva.

Regina Barbosa - Formei-me em Psicologia e iniciei minha formação em Saúde Pública em 1979, quando ingressei no curso de Residência em Saúde Pública da ENSP. Era o início do processo de redemocratização do país e os movimentos políticos - inclusive o da Reforma Sanitária (re)organizavam-se em torno de pautas reivindicativas.

Esse intenso momento histórico contribuiu para a busca de referenciais críticos que nos ajudassem a compreender nossa sociedade e nosso papel político. Ainda na Residência, engajei-me em um trabalho educativo na Unidade de Saúde da ENSP, quando organizamos um grupo de reflexão de mulheresusuárias, que resultou em mobilização e ações políticas. Pouco depois, tive o privilégio de participar de uma oficina com Paulo Freire, recém-chegado do exílio, o que foi uma experiência marcante e inesquecível. Desde então, a Educação Popular se tornou o meu "modo de andar a vida", uma referência político-pedagógica que me orienta em todos os espaços em que atuo, inclusive os acadêmicos.

Ivanilde Batista - Sou pedagoga e servidora da Secretaria Estadual de Saúde de Goiás. A vida e o trabalho me levaram para espaços da saúde coletiva, onde a cada dia um novo desafio se apresenta. Por meio da militância política no Movimento Popular de Saúde (Mops) nasceu oportunidade de participar da luta pela Reforma Sanitária, $8^{a}$ Conferência Nacional de Saúde (1986) e I Conferência Municipal de Saúde do Trabalhador/Goiânia (1998). Também contribui com a fundação do SINDSAÚDE/GO em 1989, onde hoje estou como secretária de formação política. 
Desde 2003, participo ativamente de um movimento chamado, Articulação Nacional de Movimentos e Práticas de Educação Popular e Saúde (Aneps), desse lugar, nasceram parcerias e projetos de extensão com a Universidade Federal de Goiás (UFG).

Esses projetos de extensão, chamados "Café com Ideias", as quatro edições da Mostra Parceria Ensino-Serviço-Comunidade - Mopesco -, o III Encontro Nacional de Educação Popular e Saúde e o I de Práticas Populares de Saúde, entre outras atividades, tiveram como objetivo contribuir com a reorientação do ensino na saúde, e a educação permanente no SUS, com a participação de movimentos populares, estudantes e professores da UFG.

Nesse caminho, uma oportunidade relevante foi participar da construção da Política Nacional de Educação Popular e Saúde (PNEPS) aprovada com louvor pelo Conselho Nacional de Saúde em 2012.

Hoje estamos realizando atividade de formação e articulação política para implantação da PNEPS com o projeto Saberes, Fazeres e Sabores: Encontros de Saberes e Práticas Integrativas, da PNEPS, em Goiás, e Articulações na Região Centro-Oeste.

Paulette Cavalcanti - O meu encontro com a Educação Popular vem da crítica ao próprio processo educacional da universidade, como estudante de medicina. Vem da inconformidade política na mistura que eu fazia com as lutas pela saúde e educação. Eu comecei a ler Paulo Freire e trago-o para junto da minha militância. No mestrado, vou discutir a participação popular e social, a formação dos conselhos de saúde. Hoje, atuo como professora e pesquisadora e na defesa do SUS público e de qualidade. Participo da Rede de Educação Popular e Saúde, do GT de Educação Popular da Associação Brasileira de Saúde Coletiva - Abrasco -, e mediante estes, articulo-me com a Aneps.

Julio Wong Un - Sou peruano, neto de chineses e índios, brasileiro, médico, poeta, educador, viajante. No Brasil desde 1994. Trabalhei com comunidades e grupos subalternos, procurando aprender com as pessoas simples, de vidas duras, e plenas de ternuras e alegrias.

No Brasil, fiz mestrado e doutorado sob a orientação de Victor Valla, procurando caminhos próprios e em diálogo com outros saberes e sensibilidade. Participei da criação da Rede de Educação Popular e Saúde em 1998. Em 1999, criei a lista de discussão na internet. Acompanhei e apoiei processos e experiências de articulação, reflexão, produção e afirmação da Educação Popular em Saúde.

De 2006 a 2007, coordenei a Rede de Educação Popular e Saúde. Desde 2011, coordeno o Grupo Temático de Educação Popular da Abrasco. Sou docente da Universidade Federal Fluminense desde 2006.

Suas trajetórias possuem pontos de convergência: o pensamento de Paulo Freire, a identidade com as lutas populares, a busca de novos caminhos para a saúde mais democrática. Que experiências vocês vivenciaram e destacariam dentro da EPS?

Ivanilde Batista - Participei do nascimento da Aneps, em 2003, integrando a organização do I Encontro Estadual de Educação Popular e Saúde e I Conferência Temática de Educação Popular e Saúde em novembro de 2003, contribui com projeto piloto VER-SUS/Brasil em 2004. Em 2004, com a efervescência da Educação Permanente, colaboramos com o projeto Saúde Pólo Macro Goiânia de educação permanente, experiência que trouxe visibilidade à Aneps e a vários movimentos populares.

Uma participação única foi a Marcha Nacional pela Reforma Agrária, onde contribuímos com a brigada da saúde, uma caminhada de 17 dias entre Goiânia e Brasília, um percurso aproximado de duzentos quilômetros, saindo de Goiânia em 2 de maio de 2005. Nesse momento, conquistamos o coração da D. Alzira, militante responsável pelo setor de saúde do MST em Goiás, que logo se integrou à Aneps, participou de diversas atividades locais e nacionais, e, ainda hoje, no Assentamento Canudos, mantemos nossas rodas e construímos processos de afetividade com as mulheres do assentamento.

Realizamos o II Encontro Estadual de Educação Popular e Saúde, em 2005, e construímos o Projeto Articula SUS: movimentos sociais em defesa do direito à saúde em Goiás em parceria com o grupo Transas do Corpo, que realizou diversas rodas de formação com movimentos populares.

Com nossa participação e articulação VER-SUS Brasil, chegam os estudantes e nasce o projeto Café com Ideias, parceria Universidade e Educação Popular. Logo a UFG percebeu a que o projeto era estratégico para contribuir com a reorientação do ensino na saúde, articulados aos trabalhadores 
da saúde, que se integraram as atividades do Projeto, entendendo que as nossas rodas dialogavam diretamente com as políticas afirmativas e que favoreciam a integração com grupos da diversidade e pluralidade do SUS.

Paulette Cavalcanti - Em 1994, eu conheci os Agentes Comunitários de Saúde (ACS) e comecei a trabalhar com eles, a partir de uma pesquisa de avaliação do Pacs (Programa de Agentes Comunitários de Saúde). Eu percebi neles o que tinha de novo no SUS, o que tinha de diferente, a grande mudança da Reforma Sanitária que a gente fazia tanta questão de construir. E aí fui ver que neles estavam os grandes educadores, e fui trabalhar com eles, aprender com eles.

Foram muitos projetos até 2000. Eu destacaria primeiro o FormaSUS, projeto de formação da CUT para os ACSs, por meio da CNTSS, no qual juntávamos o ensino médio com uma formação política muito boa, referenciada na Educação Popular. Esse projeto teve como grande resultado a formação dos Sindicatos de Agentes Comunitários de Saúde - o Sindacs-PE.

Destaco também os projetos que nasceram da gestão democrática e popular da Prefeitura do Recife, entre 2001 a 2008. Foi traçado um plano de formar núcleos, em cada comunidade, chamados de núcleos de cultura e Educação Popular, os Nuceps. Não chegaram a funcionar efetivamente, não colou como a gente queria, mas a ideia era de organizar grupos da população, que frequentavam o posto, não por doença, mas pela saúde, pelas coisas que precisavam lutar para ter saúde. Fazíamos oficinas com toda a equipe, incluindo até o pessoal de apoio. Discuto esse período na minha tese de doutoramento.

Logo depois, começam os que considero mais importantes e que continuam até hoje: o Aesa (Adolescente Educador em Saúde), lesa (Idosos Educadores em Saúde) e Esam (Educadores em Saúde da Mulher). Surgem da ideia de trabalhar com adolescentes e de que os ACSs eram os profissionais forjados para serem educadores. Também em oficinas, um primeiro grupo de trinta ACSs buscou entender o que era EP, seus princípios, essa construção com o saber do outro, essa perspectiva de diálogo, de respeito ao que o outro já sabe.

Discutem-se também os temas próprios da adolescência e técnicas de formação de grupo. Após a formação, batizam-se de educadores de Aesa, e vão multiplicando-se. Cada ACS, sozinho ou em dupla, vai formando grupos na comunidade. Cada ciclo de formação tinha uma formatura muito bonita, com todas as pompas. No começo, nós, técnicos, criticávamos as formaturas. Mas eles mesmos diziam: criticávamos porque já tínhamos tido a oportunidade de muitas formaturas... Eles estavam tendo a primeira oportunidade de se formar e queriam mostrar para a sociedade, familiares, que eles agora eram outra coisa: educadores.

Do Aesa veio o lesa, o Esam, os PES - Pequenos Educadores em Saúde - e os HES - Homens Educadores em Saúde. O único que não vingou foi os Educadores em Saúde Ambiental, ESAmb, mas que derivaram para grupos de teatro, cordel e outras formas de educação em saúde.

Os projetos foram se multiplicando, primeiro por três distritos e depois pelos outros distritos do Recife. Foram incorporados pelo Curso de Formação Técnica de Agente Comunitário de Saúde e geraram subprojetos de teatro, rádio comunitária, mostras anuais de arte, cultura e educação em saúde, além de muitas lutas por saúde na comunidade.

Julio Won Un - Trabalhei com a lógica da Educação Popular - ou dos seus parentes: saúde comunitária, saúde rural, participação popular, ação nos campos da arte e cultura populares, etc. desde a adolescência. Aos 14 anos, com os meus tios, sindicalistas da educação, acompanhei marchas, cursos, manifestações pela democracia. Quase fomos presos. E as bombas de gás eram presença frequente. Um velho professor subiu num banquinho e veio falar para o grupo assustado, de Paulo Freire, dos sonhos por uma sociedade diferente, onde o homem simples pudesse Ser. Fiquei marcado.

Ao longo da graduação, tive o privilégio de visitar e trabalhar em comunidades faveladas e rurais no Peru. Investi, por gosto e por opção, no trabalho cultural, desde a poesia, a crônica e a música. Sempre fui contra o uso da arte como propaganda e contra o uso perverso dos valores éticos e das propostas radicais dos autores que líamos com fervor e utopia. 
O trabalho cultural me levou por caminhos inusitados: conheci músicos indígenas, que eram míticos, toquei com grandes artistas, fiquei amigo de intelectuais, pintores, poetas, escritores. A vida sempre me sorriu e abençoou com encontros notáveis.

Ainda no internato, desenvolvi atividades de educação e atenção primária com camponeses na região da serra central do Peru, na aldeia de Marco. O sonho do jovem que cresceu em um conjunto de prédios foi sempre o de mergulhar no céu azul intenso dos Andes peruanos.

Ao me formar, trabalhei primeiro em ONGs com projetos de Educação Popular em Saúde, com crianças. Depois, quase desistindo, surgiu a possibilidade de ir de novo ao mundo rural, e trabalhei um ano com camponeses, agentes de pastoral, e profissionais da saúde tanto na região andina de Cajamarca e depois em Cuzco - a cidade imperial - e nos vales e povoados ao redor.

Nessas experiências, trabalhei medicina popular indígena, uso culturalmente apropriado de medicamentos, teatro camponês, rádio comunitária e indígena. Produzimos vários materiais com participação da população e agentes de pastoral da saúde. Foram anos marcantes. Tudo deslumbrava.

Depois, entre 1992 e 1994, fui gerente de programas de saúde nacionais da Igreja Católica com temas como doenças infecciosas endêmicas, desenvolvimento humano e saúde, dentre outros.

Já no Brasil, participei, além das reflexões e discussões de Victor Valla e seu grupo, de projetos de pesquisa e intervenção nas favelas cariocas. Ainda, articulando a Rede de Educação Popular, ajudei, moderando debates pela internet, com cursos e participações em eventos. Na universidade, o que pauta meu fazer é esse olhar da Educação Popular.

Regina Barbosa - Desenvolvi toda a minha atuação profissional e acadêmica na confluência da Educação Popular com o campo de gênero e saúde, este originado no feminismo. Não casualmente, são campos epistemológicos que, assim como a vertente marxista dialética, expressam os anseios libertários dos segmentos explorados e oprimidos da sociedade.

Já ao ingressar na UFRJ, em 1986, participei de ricas experiências educativas na Unidade de Saúde-Escola, situada na Maré, onde desenvolvíamos grupos de reflexão com as mulheres-usuárias, mobilizávamos a população para participar da gestão da unidade, criávamos modelos terapêuticos inovadores, como "consultas coletivas", entre outras.

Posteriormente, juntamente com Karen Giffin (orientadora e parceira de trabalho), desenvolvemos e implementamos um modelo de pesquisa-ação (PA) baseado em oficinas de reflexão de gênero, realizadas em pequenos grupos e com participantes já sensibilizados para os temas propostos pela PA. Nessa proposta, partimos de um processo de reflexão grupal em que os/as participantes compartilham e problematizam suas experiências privadas, ou seja, as relações familiares e conjugais, a sexualidade, o corpo, etc.

Gradativamente, o processo reflexivo se amplia para outros âmbitos da vida social, ampliando a consciência crítica sobre o mundo em que vivemos. Os/as participantes dos grupos geralmente são "agentes sociais", ou seja, pessoas que atuam profissional ou politicamente no campo temático da PA, o que é fundamental para se assegurar os desdobramentos posteriores da proposta de ação, que será elaborada por cada grupo.

Assim, as oficinas de reflexão de gênero geram um processo de (auto)reflexão que problematiza (e nos problematiza!) a difícil e complexa sociedade em que vivemos, buscando compreender, a partir das experiências do cotidiano, da subjetividade, do corpo e da saúde, como se produzem e reproduzem as várias dimensões das desigualdades sociais, entre elas as de gênero.

Esse gradativo processo de estranhamento-desvelamento-compreensão ancora as estratégias de ação que são, posteriormente, construídas nos/pelos grupos. Esse modelo de pesquisa-ação tem sido implementado em diversos espaços, envolvendo variados sujeitos e temáticas de saúde que sempre são relacionadas ao enfoque de gênero: mulheres do Complexo da Maré atuando na promoção da saúde e dos direitos das mulheres; homens de vários segmentos sociais e profissionais engajados na problematização das "masculinidades", identificando suas interfaces com a saúde dos homens e colaborando para a elaboração e implementação de um programa de saúde que considere suas necessidades e anseios; jovens moradores da Maré refletindo sobre suas identidades sociais e de gênero, sexualidade e saúde, contextualizando essas questões nos espaços de discriminação e violência em que vivem e atuando com outros jovens para promover uma consciência crítica e engajada; 
mulheres da Maré atuando no enfrentamento do tabagismo feminino sob os enfoques pedagógicos de gênero e da Educação Popular; profissionais da Estratégia Saúde da Família, com especial foco sobre Agentes Comunitárias de Saúde, atuando no enfrentamento da violência de gênero e na promoção dos direitos das mulheres.

Selvino Heck - Destacaria três experiências mais importantes. A primeira: morar nas vilas populares da Lomba do Pinheiro, entre Porto Alegre e Viamão, final dos anos 1970 e anos 1980, ajudando a construir organizações populares, participando das lutas do povo por saneamento, postos de saúde, transporte coletivo, educação de qualidade.

A segunda: a criação do Centro de Assessoria Multiprofissional (Camp), que completou 30 anos em 2013, sempre apoiador das causas populares, da economia solidária e construtor de processos formativos com base na Educação Popular freireana. A terceira: a Rede de Educação Cidadã (Recid), criada em 2003, inspirada por Frei Betto - "É preciso matar a fome de pão e, junto e ao mesmo tempo, saciar a sede de beleza" -, que atua na construção de políticas públicas de segurança alimentar e nutricional (Fome Zero), economia solidária, saúde, agricultura familiar, ambientais, direitos humanos, e no apoio à formação e organização de catadores, pescadores, quilombolas, indígenas, povos e comunidades tradicionais, moradores de periferias, agricultores familiares e camponeses, jovens e mulheres, especialmente das periferias.

A Educação Popular freireana soldou as três experiências. Hoje, quando encontro as antigas lideranças da Lomba do Pinheiro, que continuam nas lutas populares e na linha de frente dos movimentos comunitários e participativos como o Orçamento Participativo, dizem:

Aqueles momentos de formação e estudo, sempre ligados à realidade e à prática, fizeram com que eu fosse gente, começasse a pensar e ser capaz de trabalhar solidariamente. A luta pelo posto de saúde da Vila São Pedro não era apenas a luta pelo posto de saúde. Era garantir um direito. Era fazer com que o direito à saúde fosse de todos. Era ligar a saúde coletiva aos cuidados com a vida das crianças, sua educação, era ter atenção à saúde e saneamento básico, era pensar na comunidade, era querer mudar o mundo.

A Recid é uma experiência inovadora. Como dizemos, um pé está no governo e um pé na sociedade. A Recid é coordenada conjuntamente por integrantes do governo e lideranças ligadas à Educação Popular e a movimentos sociais e atua com processos de Educação Popular em todo país, com formação, na articulação e formulação de políticas públicas com outras redes como a Aneps, o Fórum Brasileiro de Economia Solidária - FBES -, os movimentos de direitos humanos. Governo e sociedade, cada um com sua autonomia, trabalham, mediados pela Educação Popular, processos emancipatórios e cidadania.

É interessante notar, nesse conjunto de experiências, o fluxo de propostas e intencionalidades da academia para os movimentos populares, ou ainda, dos movimentos para a academia, articulando sempre novos atores no processo. A partir dessa perspectiva dialógica, como podemos pensar as fortalezas e potencialidades da EPS?

Selvino Heck - A Educação Popular, com base na pedagogia libertadora de Paulo Freire, está presente ou mesmo é a base dos movimentos sociais, das pastorais populares, das lutas e processos emancipatórios que surgiram no meio da ditadura brasileira nos anos 1970, garantiram a redemocratização, produziram governos democrático-populares que construíram políticas públicas com participação popular e inovaram com o Orçamento Participativo. E tiveram ou têm influência nos processos de mudança na América do Sul e Latina. Muitas das principais lideranças políticas, produzidas no Brasil nas últimas décadas, tiveram relação ou surgiram no contexto da Educação Popular freireana.

A democracia brasileira deve muito à Educação Popular, assim como as políticas públicas implantadas no Brasil nas últimas décadas, inclusive as de saúde, especialmente a partir do governo Lula. Os princípios da Educação Popular libertadora soldaram práticas nos movimentos sociais que ajudaram a consolidar a tenra democracia brasileira e influíram decisivamente na organização e 
consciência popular, na luta por direitos, em melhorias na qualidade de vida do povo, historicamente sem voz nem vez.

Partir da realidade, dialogicidade, construção coletiva, princípios básicos da Educação Popular freireana, mais os princípios da amorosidade e da emancipação dão consistência às políticas públicas, garantem um sentido de transformação e mudança e formam povo e nação soberanos, com lideranças capazes de escutar, capazes de entender a comunidade e atender às diferentes dimensões do ser humano. Porque a Educação Popular é uma prática social presente nos diversos movimentos da sociedade.

Antes de se tornar direito adquirido, ela é uma prática social e cultural. O seu papel na transformação significa a criação de uma nova ordem. Ela não é, portanto, um assunto exclusivamente político e econômico. Implica também uma dimensão ética e cultual. A Educação Popular reconhece a vida cotidiana e a experiência como espaços de construção de uma nova hegemonia ou nova maioria. Ela valoriza a cultura popular como fonte de identidade e força de um projeto nacional popular.

Ivanilde Batista - Considero importante a integração dos coletivos de Educação Popular, a participação e construção solidária das Tendas Paulo Freire em espaços de congressos, conferências e outros eventos nacionais, estaduais e locais.

A articulação com a Rede de Educação Cidadã (Recid) amplia o leque de participação de outros movimentos como: Comitê Goiano Contra a Privatização; Movimento das Mulheres Camponesas; Pastoral da Terra; Fórum Goiano de Economia Solidária e Fórum Goiano de Saúde Mental e outros, que, por meio de debates e discussões políticas, resultaram em alguns desafios como articular e mobilizar as pessoas, em torno das discussões da saúde, valorização da cultura popular, saberes e práticas populares de saúde, ampliar as parcerias pelo o fortalecimento das estratégias (ponto de união) entre e os diversos movimentos sociais populares e atores sociais rurais e urbanos que possam se interessar pelo tema da saúde.

Outro fator importante é o apoio político e financeiro do Ministério da Saúde, a construção do Comitê de Nacional de Educação Popular e Saúde para a construção e na implementação da PNEPS. No caso de Goiás, tem-se uma potência concreta que é a criação de vários núcleos livres (disciplinas optativas) de Educação Popular e saúde no curso de Odontologia, Enfermagem e Educação, especificamente na graduação em Pedagogia da Terra e mestrado profissional em saúde da UFG.

Paulette Cavalcanti - Acho que a Educação Popular, com seus princípios que eram muitos caros para a gente, é que gerava os avanços reais. Por exemplo, na formação de cada grupo, tinha-se um levantamento dos principais problemas da comunidade e se fazia um planejamento das lutas que precisavam se travar nessas comunidades para defender a saúde. Então, podia ser uma passeata, reivindicando que os ônibus respeitassem os direitos dos idosos à passagem gratuita, podia ser um sarau onde cada um levava sua contribuição cultural, ou um movimento contra a violência contra as mulheres...

Acho que a EP muda a perspectiva de mundo das pessoas, que passam a se ver em um mundo que podem transformar, com o qual não precisam simplesmente se conformar. E isso muda tudo. As pessoas saem de casa, vão estudar, participar de conferências, do orçamento participativo, das associações. Mas podem também ir à praia, ao teatro, ao cinema, a lugares que nunca tinham ido porque, apesar de públicos, não eram vistos como delas.

A EP, em Recife, no contexto de uma Prefeitura popular, entendia que o compromisso era contribuir na libertação das pessoas, na equidade de todas as formas. Podia ser que a gente tivesse sonhando, muita gente achava esquisito fazer isso a partir do Estado, de um setor, de uma secretaria de saúde. Mas vingou até hoje e deu um bocado de frutos. Eu acho que tiveram muitos resultados. Desde os considerados mais concretos como de reduzir indicadores de saúde, como gravidez na adolescência, vacinação de idosos, vacinação antirrábica animal... Até o próprio processo mesmo de participação.

Os idosos invadiram a conferência municipal da pessoa idosa, os jovens tomaram conta do Orçamento Participativo da Juventude. E por aí afora. Saiu da saúde e foi para as políticas sociais, da mulher, da juventude, da pessoa idosa... Acho que esse é o grande avanço, resultado real, a possibilidade de organizar a população nessa perspectiva de luta pela saúde. 
Julio Wong Un - A Educação Popular, ou Pedagogia Crítica, é de uma radicalidade e atualidade assustadoras. Viver genuinamente suas propostas (eticamente exigentes e cobrando dos educadores humildade, escuta verdadeira, partir dos saberes dos educandos, pensamento crítico) demanda mudanças importantes no Ser Humano.

E, no mundo veloz, caótico, fragmentado, pleno de miragens e armadilhas em que vivemos isso não é nada fácil.

Bom exemplo dessas miragens é a institucionalização da EPS no campo da Saúde Pública. O que isso significa? Que as propostas, formas de fazer, prioridades e lutas dos militantes e simpatizantes da EPS são incorporadas à máquina do poder das várias esferas do poder. Uma máquina finamente construída a milhares de mãos há pelo menos cento e cinquenta anos.

Ao ficar "dentro" do mundo institucionalizado, é verdade que a EPS e seus agentes produzem mudanças - algumas valiosas, outras formais. Mas maiores mudanças - destruidoras - são feitas com a EPS, o que pode representar o desmantelamento de relações, confianças e simpatias lentamente elaboradas, com o ritmo da história cotidiana, com o afeto que somente o vagaroso oferece. Só um exemplo.

O princípio de tudo o que fiz na vida foi o respeito radical pelo saber e cultura dos Outros: a consciência, praticada com disciplina, de que há sempre muito que aprender dos Outros, especialmente - privilégio nosso na saúde - das pessoas simples, em sofrimento, periféricos aos poderes abertos.

Penso que, hoje, a Educação Popular é um olhar. Um olhar profundo debruçado no mundo. Olhar que incorpora a ética (respeito, humildade, honestidade), a política (questionar todos os poderes, evitar os jogos sujos da política, perceber as maldades instituídas sob a maquiagem do técnico e do aparentemente neutro), e a estética (o diálogo, a alegria, o afeto, formas verdadeiras e não formais de Amor, a preocupação pela dimensão estética do mundo, das pessoas e suas relações) que Paulo Freire e outros foram cimentando e construindo ao longo de décadas.

Ao querer transformar a Educação Popular em forma de poder, ela desvirtua-se. Ao concorrer por poderes, recursos, favores, trocas vantajosas, e ao transformar formas culturais frágeis e mutáveis em formas de propaganda, aparentemente únicas e superiores, repetitivas e cansativas, os poderes - sejam públicos ou privados; sejam pequenos ou grandes; sejam ditos ou escondidos - sacrificam o que há de melhor nesse Olhar profundo sobre o Humano e o Mundo.

Não há fórmulas, não há vacinas. Só um olhar atento e cuidadoso, de humildade e distanciamento com os poderes pode permitir que tenhamos avanços democráticos e reais.

Regina Barbosa - Como já disse antes, penso que a Educação Popular é um campo de conhecimentos e práticas que expressa os anseios e utopias dos segmentos sociais dos quais, historicamente, vivem do seu trabalho, mas não usufruem da riqueza que produzem. É, portanto, um campo crítico e que anseia por um outro modelo de sociedade, baseado na justiça social e na solidariedade. Sendo um campo contra-hegemônico, seu avanço ou recuo depende dos enfrentamentos, dos embates e das eventuais conquistas dos movimentos sociais. A Constituição de 1988, por exemplo, resultou de um processo de reorganização e de lutas dos movimentos sociais que garantiu importantes conquistas jurídico-institucionais, inclusive o direito universal à saúde e o dever do Estado em promovê-lo.

Porém, a partir da década de 1990, temos constatado perdas e retrocessos na efetivação desses direitos. Sendo o campo da Educação Popular e Saúde fundamentalmente constituído por profissionais e movimentos sociais enraizados na vida cotidiana das comunidades e comprometidos com "um outro mundo possível" (lema do Fórum Social Mundial), tem um papel fundamental na promoção da consciência crítica e no fortalecimento do protagonismo popular nas lutas por melhores condições de vida e saúde.

Os laços de solidariedade, construídos e fortalecidos na convivência do dia a dia e no enfrentamento conjunto dos inúmeros problemas e carências que afligem a população, são valores fundantes da EPS e que a tornam, a meu ver, um fundamental espaço de resistência diante disso mundo tão desagregador, discriminatório, violento e injusto. Se, hoje, está difícil antevermos uma transformação radical desse modelo de sociedade, sabemos que as estratégias de resistência que preservam valores fundamentais à nossa sobrevivência são imprescindíveis e penso que a EPS é uma inestimável contribuição nesse sentido. 
Então, a partir destas fortalezas e também desafios, o que precisa ser posto em reflexão e ação para que a EPS se capilarize cada vez mais nos serviços e práticas de saúde?

Julio Wong Un - O que falta? Muito. Avançamos muito em vários sentidos. Dentro da academia, nos serviços, nas políticas de saúde, nos movimentos sociais e grupos comunitários. Hoje, não é mais estranho ouvir ou falar de Educação Popular em Saúde. Dispositivos como tendas, teatros e comparsas, terapias e formas de cuidado viraram "normais". Entretanto, foram simplificados, superficializados, muitas vezes, ou, pior, tergiversados ou distorcidos.

É urgente e preciso empreender processos de democratização verdadeira, quebrando a lógica dos poderes do Estado e da política "como ela é". Construir caminhos de criação e de relações isentas do parasitismo político e social; e que questionem a vaidade embutida nos gestores, profissionais e em muitos intelectuais da Saúde Coletiva.

Penso que ainda se pensa a Educação Popular como coisa simplória, espetáculo a favor de melhorar a imagem de alguns políticos e gestores, forma de maquiar processos de exploração e de imposição de práticas verticais e opressivas. Ou, ainda, formas de "distrair" as massas e diminuir conflitos e tensões sociais.

Assim, enquanto houver pessoas e grupos que lucram egoisticamente com formas de dizer da EPS, com seus métodos, com suas tecnologias culturais, construídas em diversos grupos culturais, não chegaremos a capilarizar, nem a participar de forma verdadeira na construção de modos mais humanos de convívio social.

Selvino Heck - Dois elementos, entre outros tantos, parecem fundamentais, são passos urgentes e necessários a serem dados. O primeiro: os movimentos sociais, as pastorais populares, as ONGs, em suas diferentes expressões e espaços de atuação - saúde, economia solidária, direitos humanos, meio ambiente, agricultura familiar, agroecologia, educação -, de forma articulada entre si, devem voltar a fazer processos de formação massivos com base na Educação Popular, como acontecia nos anos 1970 e 1980 em especial. Esses processos de formação devem relacionar as práticas cotidianas e locais com uma visão de mundo e com processos de formação globais. Devem ligar o micro com o macro. Devem ser de base e permanentes. Devem alimentar a utopia e a esperança.

O segundo: a construção de uma política pública de Educação Popular. Nesse sentido, um passo foi dado com a deliberação da $1^{\text {a }}$ Conferência de Educação, que reconheceu, em 2010, a importância da Educação Popular como política pública no documento final, conforme o Eixo I - O Papel do Estado na Garantia do Direito a uma Educação de Qualidade:

Considerando os processos de mobilização social nas últimas décadas, que visavam à construção da educação popular cidadã, formação da cidadania e dos direitos humanos, o novo Plano Nacional de Educação (PNE) deve articular a educação formal com experiências de educação não formal, ou seja, as experiências de educação popular e cidadã, incorporando-as como políticas públicas.

Transformar a Educação Popular em política pública significa e requer o papel do governo com mediações e passos necessários, sem que se retire a autonomia e a voz própria das organizações sociais e populares: a construção dialética e descentralizada (sociedade/Estado) na formulação execução e avaliação da política; pessoas como sujeitos e não objetos do processo; ruptura com as práticas autoritárias (sociedade/Estado); disputa por hegemonia política e cultura na sociedade e no Estado para efetivação da proposta.

Uma política pública de Educação Popular é o reconhecimento do Estado, tal como fez nos anos 1960, com Paulo Freire no governo federal, e nos anos 1980, com Paulo Freire como secretário municipal em São Paulo, de que a Educação Popular tem um espaço de formulação como de articulação presente em todas as políticas públicas e na construção de um projeto de desenvolvimento democrático e popular e de uma sociedade justa e igualitária.

O exemplo do Comitê Nacional de Educação Popular em Saúde (CNEPS), instituindo uma Política Nacional de Educação em Saúde, aprovada no Conselho Nacional de Saúde, a existência de um Departamento de Educação Popular e Mobilização Cidadã na Secretaria Geral da Presidência da 
República, que coordena uma Rede de Educação Cidadã, são exemplos e experiências de como é possível capilarizar e tornar participativos os processos de Educação Popular. Exemplos a serem seguidos, estimulados, reconhecidos, divulgados.

Ivanilde Batista - Para capilarizar a Educação Popular e Saúde (EPS), deve-se mudar a forma de organizar políticas de gestão que não dão conta de toda de dimensão das necessidades reais da população que tem o direito de ser atendida pelo SUS.

Para superar essa lacuna e fortalecer a EPS, seria importante fortalecer os conselhos de saúde, criar ciclo de diálogo, análise políticas, ações e gestão participativas, no âmbito das estruturas institucionais de governo, buscando um processo de democratização das relações. Assim, sensibilizar todos os níveis da sociedade civil, desde as comunidades até os setores públicos e privados, esclarecendo importância da participação popular no controle social das políticas públicas.

A Educação Popular propõe um processo de participação mediante o qual os interessados protagonizam as ações educativas. Essa participação não é um processo uniforme. Pelo contrário, abrange uma sequência de abordagens que vão desde a construção, divulgação de informação, a colaboração, a coordenação, a consulta, a representação política até a pesquisa participativa.

É fundamental a participação dos movimentos sociais populares na formulação, implementação e acompanhamento, pensando estratégias para a inclusão de grupos sociais em situação de exclusão ou vulnerabilidades. Mas o processo democrático, em diversas situações, é construído localmente e sabemos que ainda existem municípios e estados da federação que as concepções políticas são conservadora, que a políticas de direitos ainda não avançaram e a Educação Popular em Saúde, por mais que esteja institucionalizada, ainda demora um pouco pra chegar, mas é um estratégia de luta das comunidades organizadas.

Penso que a Aneps, nesses dez anos, tem contribuído de forma efetiva na construção do SUS, no fortalecimento da Educação Popular e Saúde e no avanço da participação popular no SUS.

Paulette Cavalcanti - Acho que tem de envolver a comunidade, de organizá-la para resolver problemas que realmente necessitem, que podem ser ações de cuidado, mas que tem de incluir o conceito ampliado de saúde e gerar lutas por direitos. Hoje, acho que os grupos de Aesa, lesa e Esam, HES, em si, são práticas de cuidado. Só que entendemos que isso vem junto com a luta política, com a perspectiva de que saúde não existe sem habitação, trabalho, cultura, lazer, educação, transporte, coisas básicas as quais sustentam a vida.

Para isso, tem que se discutir a opressão, a diferença entre as classes, a exploração, a sociedade exploradora. Pode-se fazer isso junto com religião, com gestão, com automassagem, com as benzedeiras, parteiras, com as professoras do ensino fundamental, com agentes de saúde, com médicos. Mas se não discutir isso, para mim, não é Educação Popular. Porque não tem a perspectiva de libertar e transformar. Eu não posso me conformar porque a minha dor passou. Preciso saber o porquê da dor, minha e do outro, e discutir como se pára com isso.

Também são necessários momentos de formação, conversas em roda, envolvimento dos profissionais e serviços de saúde com as pessoas da comunidade, e vice-versa. É preciso ter um compromisso ético-político com uma sociedade sem exploração, sem opressão.

Outra coisa muito importante, que fizemos no Aesa/lesa, é trazer, para a coordenação, o próprio usuário. Descentralizar o poder de verdade. Montamos uma que não era só profissional e gestor, muito menos só gestor. Reuníamos, cada mês numa comunidade diferente, com os representantes, com os adolescentes, idosos, mulheres e ACSs representando cada grupo. Era uma coordenação colegiada, onde o usuário realmente definia: esse mês a gente vai fazer isso, aquilo... e a gestão implementava. E isso gerava uma unidade entre os grupos, trocando também experiências.

As Mostras de Arte e Educação em Saúde, a inclusão da EP no curso de formação técnica em ACS, a participação no OP, nas conferências e até mesmo, depois, nos congressos da Abrasco e nos encontros nacionais de EPS eram discutidos nessa coordenação colegiada. E respeitados. Não adianta discutir e não implementar como hoje é feito nos conselhos de saúde. 
Regina Barbosa - Este é um debate complexo e as respostas às questões acima envolvem várias dimensões de análise, da política e do papel do Estado aos conflitos urbanos e rurais. Em primeiro lugar, há de se considerar que existem realidades distintas e diversas pelo país afora, marcadas por conjunturas políticas locais que propiciam diferentes espaços de atuação. Penso que a EPS, de muitas formas, entrelaça-se a esses contextos e conjunturas e com eles interage, fortalecendo-se ou, ao contrário, fragilizando-se.

Mestre Paulo Freire nos ensinava que o trabalho pedagógico, na perspectiva da Educação Popular, requer, em primeiro lugar, um profundo compromisso com a justiça social. Este é, sem dúvida, o primeiro passo, mas não suficiente. A meu ver, temos enfrentado grandes desafios e dificuldades para a efetivação de uma política de EPS, sendo um dos mais importantes e graves o processo de privatização da saúde pública em curso, que, entre outras consequências, fragiliza o vínculo de trabalho dos profissionais de saúde e, como decorrência, seu envolvimento e compromisso com a população.

Assim, é fundamental uma política de Estado que assegure o Sistema Único de Saúde com financiamento público e vínculo de trabalho estável, de forma a viabilizar a consolidação, a continuidade e a ampliação das políticas de saúde, inclusive a de Educação e Saúde.

A capilaridade da atuação só pode ser garantida, a meu ver, nessa perspectiva. Na Estratégia Saúde da Família do Rio de Janeiro, por exemplo, temos acompanhado esforços e investimentos em trabalhos educativos comprometidos com a EPS que, em função da precariedade e instabilidade dos vínculos profissionais, são descontinuados. Além do mais, a escalada de violência nos espaços populares da cidade e a efetiva ameaça de poderes armados compromete a atuação dos profissionais e educadores.

Recentemente, foi denunciado, na imprensa carioca, a invasão policial na residência de dois jovens fotógrafos, moradores e militantes dos movimentos sociais do Complexo da Maré, destruindo inclusive seus instrumentos de trabalho. Esse tipo de situação faz parte do cotidiano do Rio de Janeiro e, banalizado, raramente ganha as páginas dos jornais.

Como podem os profissionais de saúde e educadores se solidarizarem com a população diante desses graves acontecimentos sem comprometer suas vidas? Essas são, certamente, barreiras reais e graves para uma maior participação da população em espaços educativos, especialmente aqueles de caráter crítico e questionador.

Por fim, não poderia deixar de lembrar que o ideário da Educação Popular aponta para um "outro mundo possível" e penso que não podemos perder essa utopia de nosso horizonte. Apesar de estarmos vivendo um momento histórico particularmente difícil e desagregador, inclusive dos movimentos sociais, creio ser nossa tarefa alimentar, nos espaços em que atuamos, a esperança e a crença em uma sociedade baseada na justiça social e na fraternidade. Esse foi o principal legado que Paulo Freire nos deixou. 
David HMSL, Batista IV, Um JAW, Cavalcanti P, Barbosa RHS, Heck S. Procesos de formación y producción de conocimiento: cinco miradas sobre la Educación Popular en Salud. Interface (Botucatu). 2014;18 Supl 2:1579-1590.

En esta edición, presentamos a cinco entrevistados con historias de origen y trayectos diferentes y praxis gira alrededor de los principios de la Educación Popular en Salud. Son: Selvino Heck, actual asesor especial de la Secretaría General de la Presidencia de la República, director del Departamento de Educación Popular y Movilización de la Secretaría Nacional de Articulación de la Secretaría General y secretario ejecutivo de la Comisión Nacional de Agroecología y Producción Orgánica; Regina Helena Simões Barbosa, profesora e investigadora del Instituto de Estudios de Salud Colectiva de la Universidad del Estado de Río de Janeiro; Ivanilde Batista, funcionaria de la Secretaría de Estado de Salud de Goiás, fundadora y militante de Aneps-GO; Paulette Cavalcanti, profesora e investigadora de la Fundación Oswaldo Cruz en Pernambuco; y Julio Alberto Wong Un, profesor e investigador del Instituto de Salud Colectiva de la Universidad Federal Fluminense.

Palabras clave: Educación Popular en Salud. Movilización social. Participación popular. 